when doses need to be prepared via dispersion of a tablet and calculation of the volume to withdraw. This may be related to the poor solubility of hydrocortisone which makes formation of a homogenous liquid difficult. There is a need for age-appropriate hydrocortisone products to be available to children.

Acknowledgement This study was funded via an unrestricted research grant from Diurnal Ltd.

\section{G220 CHANGING PATTERNS OF GROWTH IN PRADER-WILLI SYNDROME}

GI Neophytou, M Frixou, MG Shaikh, A Kyriakou. Developmental Endocrinology, University of Glasgow, Glasgow, UK

\subsection{6/archdischild-2018-rcpch.215}

Introduction/aim Children with Prader-Willi syndrome (PWS) show alterations in infantile, childhood and pubertal growth. Growth Hormone (GH) therapy is recommended due to reported improvements in height velocity (HV) and body composition. The aim was to describe the patterns of growth in PWS and the influence of both changes in clinical practice and $\mathrm{GH}$ therapy.

Methods Height SDS(HSDS), BMISDS and HVSDS of children attending a dedicated PWS clinic, 2000-2017, were analysed. To identify changes in growth we compared growth parameters between 2000-2012 and 2013-2017. In 21 children who received $\mathrm{GH}$ (median age at $\mathrm{GH}$ start 4.92 years $(2.27,8.1)$ ), consecutive measurements were available at $-1,0,+1$ and +2 years from $\mathrm{GH}$ start.

Results Overall, 60 children(31 F/29 M) were included. Three phases of growth after the age of 1 year were identified: 15 years, with acceleration in both $\operatorname{HSDS}(\mathrm{r}, 0.310, \mathrm{p},<0.0001)$ and BMISDS(r, 0.602, p,<0.0001); 6-12 years, with stabilisation in both $\operatorname{HSDS}(\mathrm{r}, 0.063, \mathrm{p}, 0.417)$ and BMISDS(r, -0.154 , p, 0.087); and 13-18 years, with deceleration in HSDS(r, -0.383, p, <0.0001) and unchanged BMISDS(r, $0.015, \mathrm{p}, 0.896)$.

\begin{tabular}{|c|c|c|c|c|}
\hline Age & 1 year & 5 years & 12 years & 16,17 years \\
\hline Number & 32 & 30 & 16 & 31 \\
\hline HSDS & $\begin{array}{l}-1.82(-3.99,- \\
0.08)\end{array}$ & $\begin{array}{l}-0.76(- \\
4.16,2.25)^{*}\end{array}$ & $\begin{array}{l}-0.59(- \\
4.27,1.59)\end{array}$ & $\begin{array}{l}-2.66(-4.27,-0.64) \\
* *\end{array}$ \\
\hline BMISDS & $\begin{array}{l}-0.83(- \\
3.27,1.85)\end{array}$ & $2.51(-2.36,5.63)^{*}$ & $1.94(-0.13,4.3)$ & $2.52(-1.5,4.18)$ \\
\hline
\end{tabular}

At age 5, children in 2013-2017 (n,12) had higher HSDS [median,-0.08 $(-1.74,1.54)$ vs $-1.04(-4.16,0.5)$ ] than those in 2000-2012 $(\mathrm{n}, 18)(\mathrm{p}, 0.03)$. At age 12, children in 2013$2017(\mathrm{n}, 5)$ had higher HSDS [median, 1.13 (-0.62,1.59) vs $-1.35(-4.27,0.23)$ ] $(\mathrm{p}, 0.027)$ and lower BMISDS [median, $1.05(-0.13,2.14)$ vs $2.44(0.13,4.3)](\mathrm{p}, 0.032)$ than those in 2000-2012 (n,11). After 2 years on GH, median HSDS improved from $-1.43(-4.59,0.95)$ to $-0.11(-3.53,1.57)$ (p, $<0.0001)$ and median HVSDS from $0.62(-5.9,4.17)$ to 2.8 $(-2.2,5.2)$ (p,0.027). BMISDS was unchanged (Table 1).

Conclusion We were able to delineate 3 distinct phases of growth in PWS. Changes in our clinical practice have led to improvements in both height and BMI. GH therapy was associated with an increase in height and stabilisation of BMI.

\section{G221 VITAMIN D STATUS OF BREASTFEEDING INFANT- MOTHER PAIRS IN SOUTH-WESTERN NIGERIA}

${ }^{1} \mathrm{OT}$ Babatunde, ${ }^{2} \mathrm{CP}$ Onyenekwu, ${ }^{3} \mathrm{LS}$ Babatunde, ${ }^{4} \mathrm{AO}$ Oyewole, ${ }^{5} \mathrm{AO}$ Oduwole, ${ }^{6}$ EU Egbuagha. 'Department of Paediatrics, Nobles Hospital, Braddan, Isle of Man, UK; ${ }^{2}$ Department of Chemical Pathology, Babcock University Teaching Hospital, Ilishan-Remo, Nigeria; ${ }^{3}$ Department of Community Medicine, Babcock University Teaching Hospital, Ilishan-Remo, Nigeria; ${ }^{4}$ Department of Paediatrics, Federal Medical Centre, Abeokuta, Nigeria; ${ }^{5}$ Department of Paediatrics, Lagos University Teaching Hospital, Idi-Araba, Nigeria; ${ }^{6}$ Department of Clinical Pathology, Lagos University Teaching Hospital, Idi-Araba, Nigeria

\subsection{6/archdischild-2018-rcpch.216}

Aims Poor vitamin D status is currently a global public-health issue including regions where the risk of vitamin $\mathrm{D}$ deficiency was previously assumed to be low due to cutaneous synthesis of vitamin D stimulated by continuous exposure to sunlight. Evidence suggests that exclusively breastfed infants are at risk of low vitamin D status; a risk factor for future poor health. No guidelines currently exist for vitamin D supplementation in Nigeria. The study aimed to determine the plasma vitamin D concentrations of study subjects, provide the much needed information on the prevalence of vitamin $\mathrm{D}$ deficiency in maternal and breastfeeding infants, as well as the relationship between maternal and infant blood vitamin $\mathrm{D}$ levels.

Methods This cross-sectional study involved 120 breastfeeding infant-mother pairs. Maternal and infant blood samples were taken at the same time. A solid phase competitive enzyme linked immunosorbent assay (DLD Diagnostika GmBH, Germany), was used for the quantitative determination of $25-\mathrm{OH}$ vitamin D in plasma, and read out using Acurex plate (Acurex Diagnostics, USA). Low and normal level controls were assayed in duplicate during each run.

Results The mean plasma vitamin D concentrations in the maternal and breastfeeding infant blood were $18.86 \pm 6.56 \mathrm{ng} /$ $\mathrm{mL}$ and $24.12 \pm 9.10 \mathrm{ng} / \mathrm{mL}$ respectively. Seven $(5.8 \%)$ mothers had normal vitamin D levels while 70 (58.3\%) mothers had hypovitaminaemia (vitamin D concentration below $20 \mathrm{ng} / \mathrm{ml}$ ). Also, $28(23.3 \%)$ of the 120 breastfeeding infants had normal vitamin D levels while $43(35.8 \%)$ had hypovitaminaemia. The mean plasma vitamin $\mathrm{D}$ concentration in breastfeeding infants was significantly higher than maternal plasma vitamin $D$ concentration $(t=5.995, p<0.001)$. There was a positive correlation between paired maternal and breastfeeding infant blood vitamin $\mathrm{D}$ concentrations $(\mathrm{r}=0.282, \mathrm{p}=0.002)$.

Conclusion The findings from this study indicate that vitamin $\mathrm{D}$ deficiency is a major public health issue in this region. Therefore we recommend that efforts be made to implement vitamin D supplementation of exclusively breastfed infants and their mothers in this region.

\section{G222 FASTING BLOOD TESTS IN CHILDREN? NO!}

T Masand, U Kumbattae. Department of Paediatrics, Royal Stoke University Hospital, Stoke on Trent, UK

\subsection{6/archdischild-2018-rcpch.217}

Aims Fasting blood tests (FBTs) are unnecessary and potentially dangerous in children. They may lead to hypoglycaemia and collapse, or delayed diagnosis of type 1 diabetes mellitus 